\title{
Characterisation of the dynamic characteristics of a complex jointed structure
}

\author{
M. S. A. Sulaiman, M. A. Yunus, M. N. Abdul Rani, A. Mohd Saman, Z. Mohamed and M.A.S. Aziz Shah \\ Center of Excellence of Dynamics and Control, Faculty of Mechanical Engineering, Universiti Teknologi MARA (UiTM), 40450 Shah Alam, \\ Malayisa
}

\begin{abstract}
Every structure that assembled with the joints has a significant effect on the dynamic behaviour of the structure. Therefore, the overall dynamic behaviour of the jointed structure highly relies on these joints. Finite element method (FEM) is commonly used to model an element connector for the jointed structure due to its because every jointed structure has its owns joint properties. The aims of this research are to identify the potential element connectors that are available in commercial finite element analysis package in order to represent the joints for spot welds and adhesive joints. The reliability of potential connector elements are quantified by comparing the predicted result calculated from commercial finite element analysis package with the experimental result that obtained from the LMS Scadas. The model of element connectors have been constructed based on three types of the case studies. The comparison reveals that the combination of Type 2 (ACM2) and Type 3 (CWELD) have shown a better capability to represent the joints of the complex jointed structure.
\end{abstract}

\section{Introduction}

In automotive engineering, the complex jointed structure, such as car hood are assembled by an arrangement of various sizes of metal sheets and they are joined by a thousand number spot welds and adhesives. Spot welds are also recognised as resistance spot welding (RSW) is a preferable choice for joining method the car hood due to its simple fabrication process. Nowadays, the modern adhesive have been used in automotive industry to reduce the number of spot welds or combined these two joints for assembling the car hood. Understandably, imperfections in assembled and jointed the structure can cause variations in dynamic characteristics, for examples, mode shapes and natural frequencies of the car hood. Besides, the reliability and the dynamic characteristics of the jointed structure greatly relies on these joints [1], [2]. For some significant time, research has demonstrated that the huge discrepancies between finite element analysis and experimental results because of the invalid assumption on modelling the joints in the finite element [3].

The main challenges to predict the dynamic behaviours is a due to the joined structure. To model a connector element for the jointed structure is very complex because every jointed structure has its own joint properties. For instance, to model the spot welds, Donders et al. had used CWELD to model spot welds for jointed the structure [4]. Besides, Heiserer et al. have proposed to use Area Contact Model 2 (ACM2) for the connector element to represent the spot welds [5]. Many researchers use this type of model to represent their model of spot welds. On the other hand, to represent the adhesive joints, Tahmasebi was proposed their model for adhesive joints to NASA Goddard Space Flight Centre [6]. Their model is in 1D element and a combination between rigid element and a spring element. However, the result of the dynamic behaviour of the model still has occurred an error.

Therefore, a continuous study about potential element connectors to represents the joints (spot weld and adhesive joints) for connector element in finite element need to be investigated. It is because the overall dynamic behaviour of the assembled structure depends on the model of the connector element [7], [8].

\section{Finite element}

Finite element analysis (FEA) or Finite element method (FEM) is a method to discretize differential operators. It is a technique used for analysis of structure by the modelling of structure. Furthermore, it is applied by engineers to finish the issues that identified with an exceptionally complex structure by utilising mathematical model and numerical method. Generally, the finite element analysis are useful to be applied in production design as to guarantee the design is a reliable model according design specifications before the manufacturing process conducted.

The complex jointed structure was constructed using finite element analysis based on a model of the hood of the car. It was developed using Altair HyperMesh 
software and OptiStruct was used to analyse the natural frequencies and mode shapes. The complex jointed structure was discretized into a shell element type which represents $1 \mathrm{~mm}$ for their thickness. The frequencies of interest are set between $1 \mathrm{~Hz}$ to $200 \mathrm{~Hz}$ and only first five modes were identified.

In this study, three types of the element connectors in FEM will be used to model the spot welds and two types for adhesive joints. Each type of element connectors will be named as Type 1, Type 2, Type 3 and Type 4 connector. Table 2 and Table 3 shows the detail of the properties and FE model for the joints.

Table 1. Details of the FE model of the complex jointed structure without the joints (Car Hood)

\begin{tabular}{cclr}
\hline $\begin{array}{c}\text { Type of } \\
\text { Elements }\end{array}$ & $\begin{array}{c}\text { No of } \\
\text { Elements }\end{array}$ & Properties & \multicolumn{1}{c}{ Value } \\
QUAD4 & 28287 & $\begin{array}{l}\text { Young's } \\
\text { Modulus }\end{array}$ & $210 \mathrm{GPa}$ \\
TRIA3 & 1700 & $\begin{array}{l}\text { Poisson's Ratio } \\
\text { Density }\end{array}$ & $\begin{array}{r}0.33 \\
\end{array}$ \\
\hline
\end{tabular}

Table 2. Details of the properties for the joints.

\begin{tabular}{lrr}
\hline \multicolumn{1}{c}{ Properties } & \multicolumn{1}{c}{ Adhesive } & Spot Welds \\
Young's Modulus & $5.96 \mathrm{MPa}$ & $210 \mathrm{GPa}$ \\
Poisson's Ratio & 0.49 & 0.3 \\
Density & $1000 \mathrm{~kg} / \mathrm{m}^{3}$ & $7900 \mathrm{~kg} / \mathrm{m}^{3}$ \\
\hline
\end{tabular}

Table 3. Details of the FE model for the joints.

\begin{tabular}{lr}
\hline \multicolumn{1}{c}{ Type of Elements } & No of Elements \\
HEXA solid element & 93 \\
WELD (1D) & 24 \\
\hline
\end{tabular}

\section{Type 1 connector}

Type 1 element connector as shown in Table 4(a) is the rigid body element type of joint. In this approach, since only rigid body element (RBE2) was used, there are no mechanical properties and mass apply to the joint. Basically, it consists of one independent node and one or more dependent nodes. This element connector was used as the initial model for spot welds and adhesive joints and to compare with the measurement.

\section{Type 2 connector}

Type 2 element connector as shown in Table 4(b). The model of element connector is for adhesive joint, and only one model has been designed. It was designed as an Area Contact Model 2(ACM2). This type of element connector is the combination of HEXA solid combined with RBE2. The patch will be jointed with the rigid element to the component. The idea of using this type of connector is the patch of solid element is represented the adhesive so that it can input and update their properties.

\section{Type 3 connector}

Type 3 connector represented for spot welds is used CWELD as type 3 connector as shown in Table 4(c); the model has already existed at HyperWorks. It is a 1D element and to construct the model is based on node to node. This element connects between two components at each node that represents the joint. The size of spot welds diameter and their properties can be updated. The detail or the properties as shown in Table 2.

\section{Type 4 connector}

Table 4(d) shows the 1D element that represents for spot welds. Same as Type 3, this type of connector has used the CWELD element, but it is modelled based on the node to the surface. The name of this model is GA-GB ELPAT. This type of connector can also input their properties and size of spot welds diameter.

Table 4. (a) Type 1 connector; (b) Type 2 connector; (c) Type 3 connector; (d) Type 4 connector.

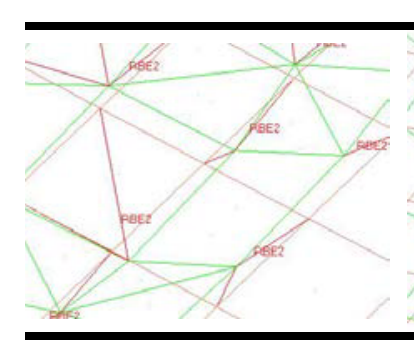

(a)

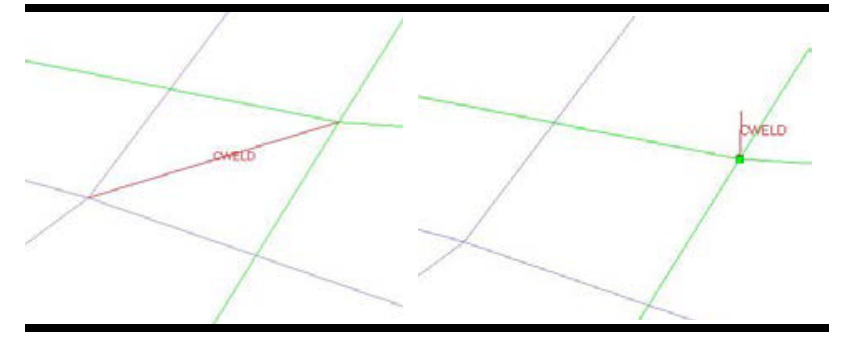

(c) (d)
It has three case studies to represent the joints for adhesive joints and spot welds. The model of element connectors has been constructed based on three types of the case study, firstly is case study 1 , secondary is case study 2 and third is case study 3 ;

- Case study 1 - Type 1

- Case study 2 - Type 2 and Type 3 connectors

- $\quad$ Case study 3 - Type 2 and Type 4 connectors

\section{Experimental works}

Experimental modal analysis (EMA) is a technique or a process to determine the dynamic behaviour of the structure, which is mode shapes, natural frequencies and damping ratios from vibration test [9]. It is also mentioned to as model testing or modal analysis. Basically, this test measures modal properties such as natural frequencies, mode shape and damping. Another explanation behind vibration testing is to check a predicted model proposed for the test framework. The result from finite element model will be verified and compared to experimental data to get a better outcome. If the result from experimental data, such as, mode shapes and natural frequencies agree with those predicted by the finite element model, the model is confirmed and can be used in design and response prediction with some 
confidence. Niw Chang Chee has used this method to verify their model is reliable, and their model can use for another experiment [10].

Prior to experimental setup, all of this process must be consider to get the acceptable result. It is the hanging orientation of the structure, the number of measuring points or nodes of the structure, the excitation method and the number of the accelerometers. Meanwhile, the roving accelerometer method and shaker testing were used to excite the structure.In this paper, the experimental work of the complex jointed structure was using shaker testing method and roving accelerometer. The structure was tested on free-free boundary conditions as shown in Figure 1 where the damping will be neglected because the structure is lightly damp. Four nylon string with springs were used to simulate the free-free boundary conditions. The frequencies of interest of the structure were between $1 \mathrm{~Hz}$ to $200 \mathrm{~Hz}$. As a guideline, the results of finite element analysis was utilised to decide the frequencies of interest and the excitation point. Besides, the mode shapes from finite element will be used as an initial idea how the mode shapes behave. The response signal for this experiment was interpreted by LMS SCADAS analysis.

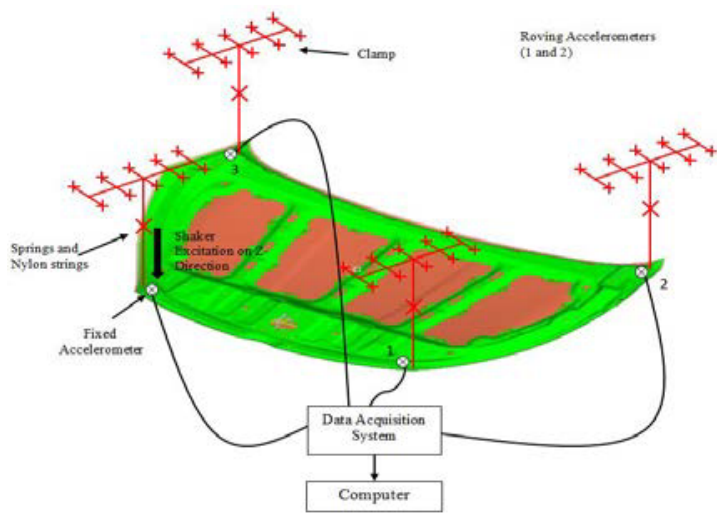

Figure 1. Schematic diagram of the complex jointed structure set up.

\section{Results and discussion}

In this complex jointed structure, the results are shown based on three types of the case study. Table 5 and Table 6 had shown the comparison of the results between test data, case study 1 , case study 2 and case study 3 . The comparison between test data and case study 1 , clearly shown that the percentage of error is very high other than case study 2 and 3 because the joint is defines a rigid body. Therefore, the complex jointed structure are very sensitive with the design of joint which it highly depend on their stiffness.

Table 5. The comparison of the natural frequencies between test data and case study 1 .

\begin{tabular}{|c|c|c|c|c|}
\hline I & II & III & IV & $\mathbf{V}$ \\
\hline $\begin{array}{l}\text { Mode } \\
\text { No. }\end{array}$ & $\begin{array}{c}\text { Test Data } \\
(\mathbf{H z})\end{array}$ & $\begin{array}{c}\text { Case Study } \\
1(\mathrm{~Hz})\end{array}$ & $\begin{array}{c}\text { Error } \\
(\%)\end{array}$ & $\begin{array}{l}\text { MAC } \\
\text { Value }\end{array}$ \\
\hline 1 & 27.163 & 41.406 & 52.435 & 0.98 \\
\hline 2 & 50.642 & 71.414 & 41.017 & 0.61 \\
\hline
\end{tabular}

\begin{tabular}{ccccc}
3 & 60.164 & 83.902 & 39.455 & 0.68 \\
4 & 80.445 & 120.666 & 49.998 & 0.94 \\
5 & 106.536 & 161.318 & 42.277 & 0.35 \\
\hline \multicolumn{5}{l}{ Total Error (\%) }
\end{tabular}

Table 6. The comparison of the natural frequencies between test data and case study 2 .

\begin{tabular}{ccccc}
\hline $\begin{array}{c}\text { I } \\
\text { Mode }\end{array}$ & $\begin{array}{c}\text { II } \\
\text { Test Data } \\
\text { No. }\end{array}$ & $\begin{array}{c}\text { III } \\
\text { Case Study }\end{array}$ & $\begin{array}{c}\text { IV } \\
\text { Error } \\
\mathbf{~ ( H z )}\end{array}$ & $\begin{array}{c}\text { V } \\
\text { MAC }\end{array}$ \\
1 & 27.163 & 29.480 & 8.530 & Value \\
2 & 50.642 & 51.230 & 1.108 & 0.97 \\
3 & 60.164 & 64.277 & 6.836 & 0.73 \\
4 & 80.445 & 82.930 & 3.089 & 0.84 \\
5 & 106.536 & 101.972 & 4.284 & 0.81 \\
\hline \multicolumn{7}{r}{ Total Error (\%) } & & 23.847 &
\end{tabular}

Table 7. The comparison of the natural frequencies between test data and case study 3 .

\begin{tabular}{|c|c|c|c|c|}
\hline I & II & III & IV & V \\
\hline $\begin{array}{l}\text { Mode } \\
\text { No. }\end{array}$ & $\begin{array}{c}\text { Test Data } \\
\text { (Hz) }\end{array}$ & $\begin{array}{c}\text { Case Study } \\
\mathbf{3}(\mathrm{Hz})\end{array}$ & $\begin{array}{c}\text { Error } \\
(\%)\end{array}$ & $\begin{array}{l}\text { MAC } \\
\text { Value }\end{array}$ \\
\hline 1 & 27.163 & 29.629 & 9.079 & 0.97 \\
\hline 2 & 50.642 & 51.265 & 1.230 & 0.73 \\
\hline 3 & 60.164 & 64.350 & 6.958 & 0.79 \\
\hline 4 & 80.445 & 83.231 & 3.463 & 0.85 \\
\hline 5 & 106.536 & 102.299 & 3.977 & 0.82 \\
\hline
\end{tabular}

Table 8. The comparison of the mode shapes between measured and predicted for case study 1 .

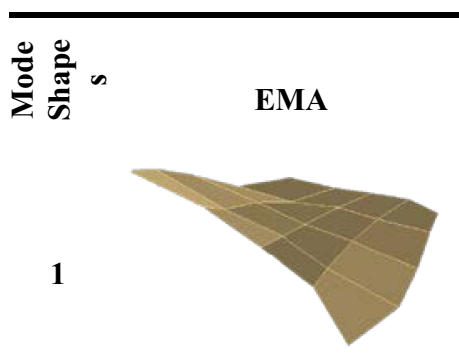

$27.163 \mathrm{~Hz}$

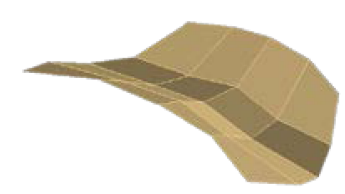

$50.642 \mathrm{~Hz}$

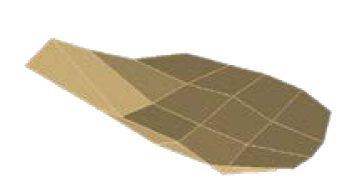

$60.164 \mathrm{~Hz}$
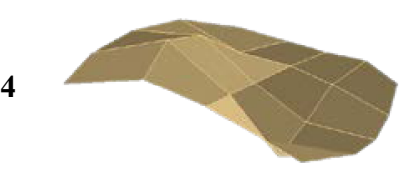

$80.445 \mathrm{~Hz}$
Case Study 1

FE

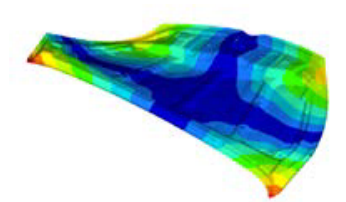

$41.406 \mathrm{~Hz}$

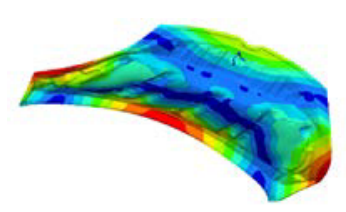

$71.414 \mathrm{~Hz}$

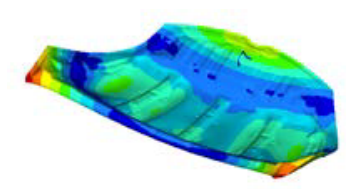

$83.902 \mathrm{~Hz}$

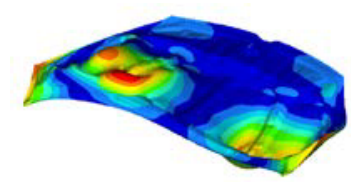

$120.666 \mathrm{~Hz}$ 


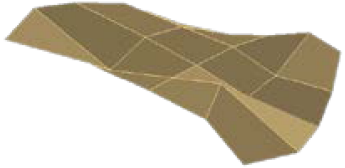

$106.536 \mathrm{~Hz}$

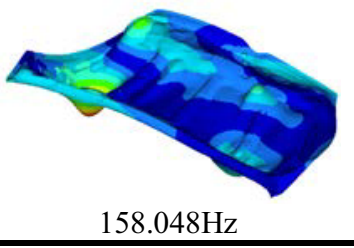

Table 9. The comparison of the mode shapes between measured and predicted for case study 2 .

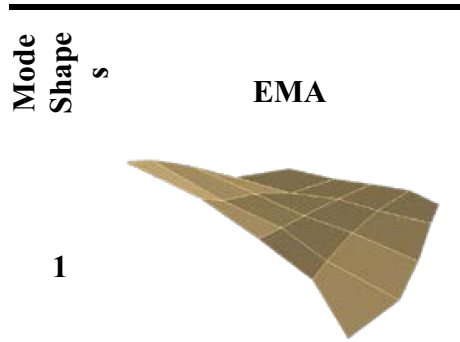

$27.163 \mathrm{~Hz}$

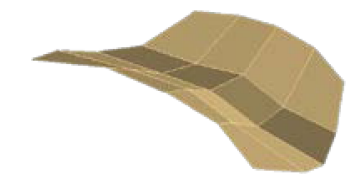

$50.642 \mathrm{~Hz}$

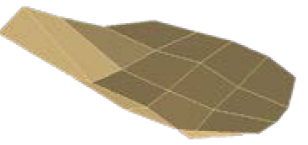

$60.164 \mathrm{~Hz}$

4

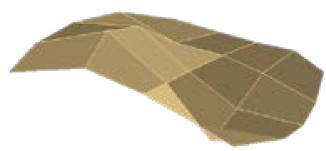

$80.445 \mathrm{~Hz}$

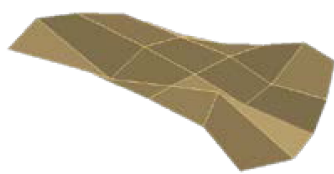

$106.536 \mathrm{~Hz}$
Case Study 2

FE

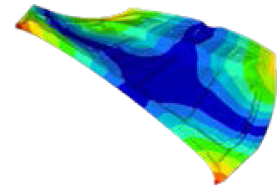

$29.480 \mathrm{~Hz}$

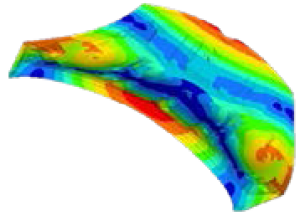

$51.203 \mathrm{~Hz}$

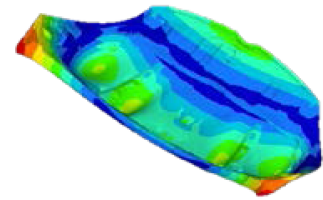

$64.277 \mathrm{~Hz}$

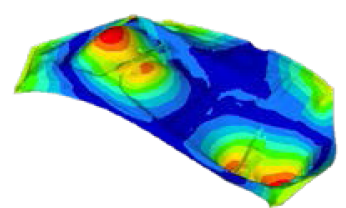

$82.930 \mathrm{~Hz}$

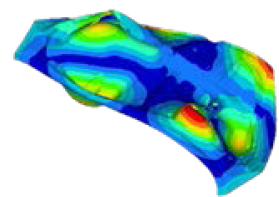

$101.972 \mathrm{~Hz}$
Table 10. The comparison of the mode shapes between measured and predicted for case study 3 .

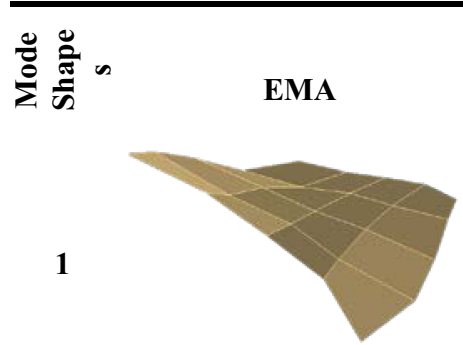

$27.163 \mathrm{~Hz}$
Case Study 3

FE

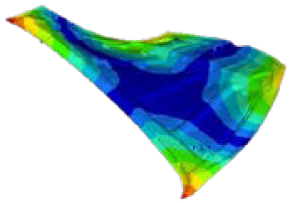

$29.629 \mathrm{~Hz}$

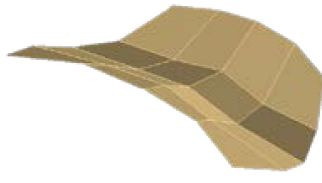

$50.642 \mathrm{~Hz}$

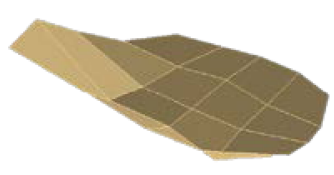

$60.164 \mathrm{~Hz}$

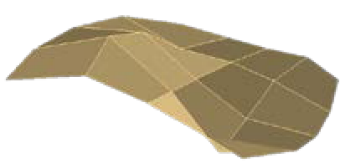

$80.445 \mathrm{~Hz}$

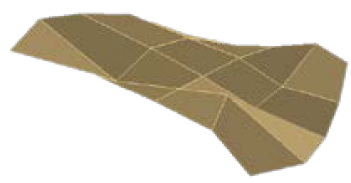

$106.536 \mathrm{~Hz}$

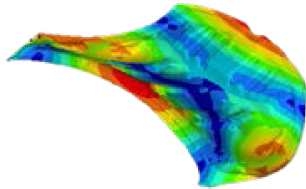

$51.265 \mathrm{~Hz}$

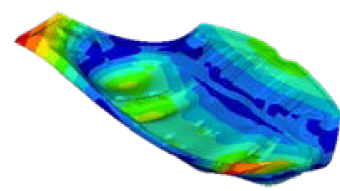

$64.350 \mathrm{~Hz}$

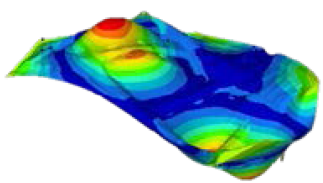

$83.231 \mathrm{~Hz}$

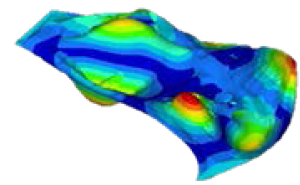

$102.299 \mathrm{~Hz}$
However, based on Table 6 and Table 7, shown that the natural frequencies of case study 2 have lower natural frequencies than the case study 3 which is 35.550 percent and 36.559 percent respectively with the MAC value above 0.8 . Besides, that its shown the highest error which in mode six. Meanwhile the mode two shown the least of 1.108 percent with a total of MAC value 0.73 . Next, for case study 3 , the highest and least error is same with case study 1 which is 11.853 percent and 1.230 percent. It happen because the overall dynamic behaviour of the assembled structure depends on the model of the connector element and the reliability a composition of the structure is greatly dependent on the joints [1]. By observing the Table 5, Table 6 and Table 7, it is agreed that the predicted natural frequencies can be vary by manipulating the element connectors. Therefore, the data for a finite element in case study 2 shows more reliable than the case study 1 and 3 . This indicates a good selection of element connectors can produce a reliable results. The result will be validated and confirm the accuracy of the finite element analysis with the experimental result by comparing the mode shapes [9]. Therefore, Table 8, Table 9 and Table 10 shows the mode shapes based on case study 1 , case study 2 and case study 3 that were did from test data and finite element results.

\section{Conclusion}

The first five frequencies of a complex jointed structure of car hood were investigated experimentally and numerically. Besides, the potential element connectors that are available in the commercial finite element analysis to represent the joints for spot welds and adhesive joints were identified. The reliability of 
potential element are quantified by comparing the predicted result with experimentally based on three case studies. The comparison reveals that the case study 2 , the combination of Type 2 (ACM2) and Type 3 (CWELD) have a better capability to represent the joints for spot welds and adhesive joints of the complex jointed structure. However, the correlation between the numerical and the experimental data can be improved by applying the finite element reconciliation method to the finite element model of the complex jointed structure which will be applied to the next stage. Moreover, the continuous study in modelling the jointed structure was recommended.

\section{Acknowledgement}

The authors gratefully acknowledge the Kementerian Pendidikan Malaysia (KPM) and Research Management Centre (RMC) UiTM for the Fundamental Research Grant Scheme (FRGS) with the file number 600RMI/FRGS 5/3 (78/2014) for the sponsorship of this research. The authors also would like to express appreciation to Mohamad Azwan Abd Khair from the Centre of Structural Dynamics and Vibration Engineering (SDAV) UiTM for their technical assistance and laboratory facilities.

\section{References}

1. M. A. Yunus, M. N. A. Rani, H. Ouyang, H. Deng, and S. James, "Identification of Damaged Spot Welds in a Complicated Joined Structure," J. Phys. Conf. Ser., vol. 305, p. 12057, (2011)

2. R. A. Ibrahim and C. L. Pettit, "Uncertainties and Dynamic Problems of Bolted Joints and Other Fasteners," J. Sound Vib., vol. 279, no. 3-5, pp. 857936, (2005)

3. M. A. Yunus, "Finite Element Modelling and Updating of Structure of Sheet Metal with Bolted and Welded Joints," (2011)

4. Y. Xia and H. Hao, "Statistical Damage Identification of Structures with Frequency Changes," J. Sound Vib., vol. 263, no. 4, pp. 853870, (2003)

5. D. D. Heiserer, M. Chargin, and D. J. Siela, "High Performance , Process Oriented, Weld Spot Approach," 1st MSC Worldw. Automot. User Conf., pp. 1-14, (1999)

6. F. Tahmasebi, "Finite Element Modeling of an Adhesive in a Bonded Joint," (1999)

7. G. Lasker, J. G. Maloney, M. T. Shelton, and D. A. Underhill, "Structural Dynamic Properties of Tactical Missile Joints-Phase 3," Ntis, no. May, p. 186, (1974)

8. D. J. Ewins, J. M. Silva, and G. Maleci, "Vibration analysis of a helicopter with an externally-attached structure," Shock Vib. Inf. Cent., vol. 50, pp. 155170, (1980)

9. K. A. Ramsey, S. M. Systems, and S. Jose, "Experimental Modal Analysis , Structural Modifications and FEM Analysis on a Desktop Computer mathematical dynamic models of structures so that they could," Sound Vib., no. February, pp. 1-10, (1983)

10. N. C. Chee, A. Bakar, and R. Holloway, "Finite element modeling of arc welded joints," J. Mek., vol. 23, no. June 2007, pp. 15-30, (2007)

11. Y. Zhao, C. Yang, L. Cai, W. Shi, and Z. Liu, "Surface Contact Stress-based Nonlinear Virtual Material Method for Dynamic Analysis of Bolted Joint of Machine Tool," Precis. Eng., vol. 43, pp. 230-240, (2016)

12. A. A. S. M. Darwish, Sh. M. Elseufy and Advanced, "Finite Element Analysis of an Automobile Engine Finite Element Analysis of an Automobile Engine Hood," no. MARCH 2013, pp. 1-8, (2016)

13. L. Majkut, "Acoustical diagnostics of cracks in beam like structures," Arch. Acoust., vol. 31, no. 1, pp. 17 28, (2006)

14. N. Rieger, "Relationship between finite element analysis and modal analysis.," Sound Vib., pp. 16-31, (1986)

15. Stephen A. Dyer, Survey of Instrumentation on Measurement. Wiley, (2004)

16. W. Kuntjoro, An Introduction to the Finite Element Method. McGraw-Hill Education (Asia, 2005)

17. N. S. Gokhale, Practical Finite Element Analysis. (2008)

18. D. Hutton, Fundamental of Finite Element Analysis. Mc Graw Hill, (2004)

19. He, J. and Z.F. Fu, Modal analysis. (ButterworthHeinemann, (2001) 